\title{
Health-Related Quality of Life and Related Factors in Thais with Stable COPD
}

\author{
Naiyana NOONIL ", Rewwadee PETSIRASAN and Saifon AEKWARANGKOON
}

School of Nursing, Walailak University, Nakhon Si Thammarat 80161, Thailand

('Corresponding author's e-mail: nnaiyana@wu.ac.th)

Received: 30 May 2017, Revised: 13 February 2018, Accepted: 31 March 2018

\begin{abstract}
This cross-sectional descriptive study aimed to describe the health-related quality of life (HRQL) and related factors of the southern Thai patients with stable COPD. The sample consisted of 126 patients with stable COPD attending the out-patient pulmonary clinic of Thasala hospital. The patients were assessed for HRQL by the Saint George's Respiratory Questionnaire (SGRQ), age, BMI, depression, dyspnea by the Modified Medical Research Council (mMRC), exercise capacity by the 6 min walk distance (6MWD), and admission. The results found that $84 \%$ of patients were male, with a mean age of 69.6 years, FEV1 70 (9.6) \% predicted, BMI 21.9 (4.4) and 6MWD 259.8 (97.9). The HRQL indicated mild impairment: symptoms 47.1 (22.4), activity 49.7 (30.3), impact 41.9 (21.2) and total scores of 45.1 (21.7). The regression analysis showed that HRQL was significantly associated with exercise capacity, depression, and MRC dyspnea respectively $\left(\mathrm{R}^{2}=0.492, \mathrm{p}<0.01\right)$. Therefore, stable COPD patients should be assessed and motivated to pulmonary rehabilitation for promoting clinical outcomes and also improving their HRQL.
\end{abstract}

Keywords: COPD, stable, quality of life, related factors

\section{Introduction}

Chronic obstructive pulmonary disease (COPD) is a leading cause of morbidity and mortality worldwide and results in an economic and social burden that is substantial and increasing [1]. In Thailand, similar to other countries in the world, COPD is also a major cause of death and places a burden on the health-care system. According to the hospital registration, the number of COPD in-patients was in the third rank and its treatment expenditure was in the first rank [2]. These patients may experience disease exacerbation 3 - 4 times per year, often requiring hospitalization 1.6 times with a length of stay 514 days and incurring costs of 7,000 - 10,000 Baht for each hospital stay [3]. As the disease develops, patients with COPD experience a corresponding reduction in health-related quality of life (HRQL) [4] which includes reduced ability to work and to participate in physical and social activities [5]. Thus, the evaluation of COPD severity alone, defined as the degree of reduction in forced expiratory volume in 1 second (FEV1), does not provide enough information to assess patients' self-perceived health status.

In recent years, HRQL has become an important measurable outcome in patients with COPD and has been defined as an individual's perception of physical and mental health [6]. The HRQL has also been defined as a holistic, self-determined evaluation of satisfaction with issues important to the person [7]. It is also known to predict mortality [8], hospitalization [8,9] and become one of the composite effects of the intervention on patient's well-being [10]. The Saint George's Respiratory Questionnaire (SGRQ) is a disease-specific measure of health status for use in patients with obstructive airway diseases designed by Jones and colleagues (1992) [11] and has been one of the most widely used. Studies have found strong correlations between HRQL and several clinical and functional variables. They have shown that dyspnea, exercise capacity, FEV1, hospital utilization, depression and anxiety are associated with the 
http://wjst.wu.ac.th

quality of life scores in these patients [12-16]. However, these previous studies were performed in Western countries which might limit the application of their findings in Eastern countries.

In Thailand, HRQL has also been identified as an outcome indicator that is sensitive to healthcare interventions, because effective treatment, as well as exacerbation prophylaxis, will meaningful improve in patient's quality of life. It is crucial to identify factors influencing HRQL in COPD patients, in the outpatient pulmonary clinics so that such factors can be efficiently manipulated in order to maximize HRQL improvement. However, limited research has been conducted regarding HRQL of COPD patients in the context of Thai society [2,3,17]. For this reason, this study aimed to examine its related factors, based on the clinical outcome indicators of the quality of life status modifications [18], as BMI, dyspnea, readmission, exercise capacity, and depression. Therefore, the purpose of this study was to explore components of HRQL and its related factors in Thai patients with stable COPD.

\section{Materials and methods}

This cross-sectional, descriptive study was performed in the out-patients pulmonary COPD clinic of Thasala hospital in Nakhon Si Thammarat province. The sample consisted of 126 participants who were consecutively attending the outpatient pulmonary clinic during November 2013 to February 2014 for follow-up. Inclusion criteria based on clinically stable COPD [19]: 1) clinical diagnosis of COPD with a percentage of $\mathrm{FEV}_{1}<80 \%$; 2) no history of asthma, bronchiectasis, tuberculosis, or other confounding diseases; 3) clinically stable (no exacerbation for at least 2 months) at the time of the evaluation and 4) convenience and pleased for 6 min walk test. The sample size was determined according to Cohen [20], using the power analysis for multiple regression. Based on 5 predictor variables entered in one regression equation, level of significance $(\alpha)$ at 0.05 , a medium effect size (ES), and power $(\beta)$ of 0.80 , a minimum sample of 91 was needed. In keeping with the powerful sampling estimate, 126 patients were recruited.

\section{Instruments}

The research instruments for collecting data were: 1) Personal information questionnaire, 2) the St. George's Respiratory Questionnaire: SGRQ, 3) the Medical Research Council (MRC) dyspnea scale, 4) 6 min walk distance (6MWD), and 5) the Thai version of the Patient Health Questionnaire as follows:

Personal information questionnaire included gender, age, status, education, and smoking history, and period of disease. Height and weight were measured and body mass index (BMI) was calculated. BMI was defined based on the National Institutes of Health, National Heart Lung and Blood Institute (NHLBI) as underweight $\left(<21 \mathrm{~kg} / \mathrm{m}^{2}\right)$, normal $\left(21-24.9 \mathrm{~kg} / \mathrm{m}^{2}\right)$, overweight $\left(25-29.9 \mathrm{~kg} / \mathrm{m}^{2}\right)$, and obese $\left(>30 \mathrm{~kg} / \mathrm{m}^{2}\right)[21,22]$. A chart review was conducted to obtain clinical data as airflow limitation from the last spirometric measurement, post-bronchodilator forced expiratory volume in one second $\left(\mathrm{FEV}_{1}\right) \%$ predicted, and admission was defined as the number of hospital admissions to the inpatient or intensive care unit in the past 12 months.

St. George's Respiratory Questionnaire (SGRQ) is a disease-specific measure of HRQL in COPD patients, containing 50 items and 76 weighted responses divided into 3 domains: symptom, activity, and impact [11]. The symptoms domain contains items concerned with the level of symptomatology, including frequency and duration of cough, sputum production, wheeze, or breathlessness. The activity domain is concerned with physical activities that either cause or are limited by breathlessness. The impact domain covers such factors as employment, being in control health, need of care, adverse drug reactions, expectations for health, and disturbances of daily life. Each item has been responded from participant as yes $=1$, no $=0$ or True $=1$, False $=0$. The scores ranging from 0 (no impairment) to 100 (maximal impairment) are calculated for each domain, as well as a total score which summarizes the responses to all items. A low score indicates a better HRQL and the score of more than 25 is used as the cut-off point for considering regular treatment for symptoms [1]. Thus, scores of HRQL were interpreted as: normal (0-24), mild impairment (25-49), moderate impairment (50-74), and sever impairment (> 75). In this study a validated Thai version of the SGRQ was used [3], the Cronbach's alpha was 0.83 . 
http://wjst.wu.ac.th

Medical Research Council (MRC) dyspnea scale has been used for grading breathlessness on daily activities [23]. This scale measures perceived respiratory disability that consists of 5 grades: grade 0 : "I only get breathlessness with strenuous exercise"; grade 1: "I get short of breath when hurrying on the level or walking up a slight hill"; grade 2: "I walk slower than people of same age on the level, or have to stop for breath when walking on the level"; grade 3: "I stop for breath after walking about 100 meters"; and grade 4: "I am too breathlessness to leave the house or when dressing or undressing". The cut-off point of MRC dyspnea is $\geq 2$ for separating "less breathlessness" from "more breathlessness" [24,25].

Six min walk distance (6MWD) is a valid and reliable tool to measure exercise capacity in patients with COPD [26]. Because walking is one of the main activities of daily living, walk tests have been proposed in order to measure the state or the functional capacity of patients. Patients were asked to walk as far as possible in $6 \mathrm{~min}$ in a hospital corridor $100 \mathrm{~m}$ long. They were instructed to walk as far as possible for $6 \mathrm{~min}$, taking rest periods if necessary. No encouragement during the test was given. At the end of the $6 \mathrm{~min}$, they were told to stop, and the distance walked was recorded. The cut-off point for the $6 \mathrm{MWD}$ was $<350 \mathrm{~m}$ as a pulmonary impairment [25].

Patient Health Questionnaire with 9 items (PHQ-9) is an instrument for making criteria-based diagnoses of depressive disorders and also a measure of depression severity commonly encountered in primary care $[27,28]$. As a severity measure, the PHQ-9 score ranges from 0 to 27, because each of the 9 items can be scored from 0 (not at all), 1 (several days), 2 (more than half the days), and 3 (nearly every day). The easy-to-remember cut-off point scores of 5, 10, 15, and 20 represent the thresholds for mild, moderate, moderately severe and severe depression, respectively [27]. The Cronbach's alpha of this study was 0.92 .

\section{Data collection}

Prior to data collection, permission was obtained from the hospital director to approach potential patients located in the out-patient pulmonary clinic. The head nurse and staff in the clinic were informed about goals and procedures associated with the research study. The medical records for patients on the daily appointment rosters were searched by the head of the research team. The potential patients were then individually approached at the time of their scheduled medical appointment. Data colleting took place in the meeting room of the hospital and the process consisted of 1) interviewed demographic, HRQL, MRC dyspnea, and PHQ-9 questionnaire and; 2) reviewed chart for clinical data; 3) measured height and weight for calculating BMI; and 4) evaluated exercise capacity by 6MWD.

\section{Data analysis}

Depending on the variable distribution, results are expressed as numbers and percentages, mean and standard deviation (SD) or median and interquartile rage (IQR). In the preliminary analysis, Pearson's product moment correlation and Spearman's rank correlation were used. Covariates that were significantly related to the dependent variables were retained in the model. A stepwise model building approach, using multivariate linear regression, was applied to examine relationships among the predictors and the each domain of HRQL. The level of significance was set at $p \leq 0.05$. Model diagnostics revealed no outliers or influential points, and the assumptions of normality, linearity, homoscedasticity (normality of residual plot), autocorrelation (or Durbin Watson 1.96) and multicollinearity (tolerance $0.71-0.85$, variance inflation factor [VIF] 1.18 - 1.53) were met and satisfied for this multiple regression analysis.

\section{Ethical considerations}

This study was approved by the Ethics Committee on Human Rights Related to Research Involving Human Subjects from Walailak University (reference no. 036/2011). Afterwards, the researcher sent the letter to the hospital director asking for permission to collect data at the out-patient pulmonary clinic. All patients were provided information including research purposes, procedure, confidentiality, risks and benefits associated the study before signing the informed consent. The patients' rights were protected and they could withdraw throughout the study without penalty. 
http://wjst.wu.ac.th

\section{Results and discussion}

\section{Demographics and clinical characteristics}

Most patients (84.3\%) were male; with a mean age of 69.6 (9.5) years, FEV1 70.0 (9.6) \% predicted, and the period of disease range was 1 - 50 years, with median 7 (16). The majority $(71.7 \%)$ had a history of smoking, while $18.9 \%$ were active smokers. Half $(51.6 \%)$ were underweight (BMI $<21$ $\mathrm{kg} / \mathrm{m}^{2}$ ), with a mean weight 21.9 (4.4). According to MRC dyspnea, 30.7\% of patients had more breathlessness (Grade 3 - 4), median 2 (2) and 20.5\% were admitted more than 2 times in the past 12 months. The mean of depression measured by PHQ-9 was 8.3 (6.0) scores, $37.8 \%$ showed moderate depression (score $\geq 10$ ). In addition, the mean of 6MWD measured exercise capacity was 256.6 (98.3), most of them $(82.7 \%)$ had distance walk $<350 \mathrm{mts}$. The HRQL measured by SGRQ scores showed mild impairment of all domains: activity 49.7 (30.3), symptom 47.1 (22.4), impact 41.9 (21.2) and total score 45.1 (21.7) (Table 1).

\section{Relationships between the components of HRQL and related factors}

The Pearson's correlation and Spearman's rank correlation analysis shows a significant correlation between the 3 domains of HRQL and admission, MRC dyspnea, 6MWD, and PHQ-9, at p-value 0.01 and 0.05 . Only BMI had a significant correlation with only symptom $(\mathrm{p}<0.05)$. The correlation coefficients of all factors are given in Table 2.

\section{Predictors of HRQL}

Table 3, regarding a total score of HRQL, the study found that 6MWD, MRC dyspnea (grade 3 - 4), and depression together explained $49.2 \%$ of the variance. The strongest predictor for better HRQL was better MRC dyspnea (grade 3 - 4). In terms of the symptom domain of HRQL, admission ( $\geq 2$ times per year), MRC dyspnea (grade 0 - 2) and 6MWD together explained $18.9 \%$ of the variance. The strongest predictor for severity of respiratory symptoms was found to be the number of admissions. In addition, the activity domain of HRQL, 6MWD, MRC dyspnea (grade 3 - 4), and depression together explained 50.7 $\%$ of the variance. The strongest predictor for improved physical activities was MRC dyspnea (grade 3 4). Finally, the impact domain of HRQL, the study revealed that 6MWD, MRC dyspnea (grade 0 - 2), and depression together explained $43.3 \%$ of the variance. The strongest predictor for the impact of the respiratory disease on the daily life was depression.

Table 1 Demographic and clinical characteristics $(n=126)$.

\begin{tabular}{|c|c|c|c|}
\hline Characteristics & $\%$ & Mean (SD) / Median (IQR)* & Range \\
\hline Gender, male/female & $84.3 / 15.7$ & & \\
\hline Age, yrs & & $69.6(9.5)$ & $50.0-93.0$ \\
\hline \multicolumn{4}{|l|}{ Education } \\
\hline None & 18.9 & & \\
\hline Primary school & 74.0 & & \\
\hline Secondary school & 5.5 & & \\
\hline Bachelor's degree & 1.6 & & \\
\hline \multicolumn{4}{|l|}{ Status } \\
\hline Single & 3.9 & & \\
\hline Married & 73.2 & & \\
\hline Widowed/Divorced & 22.9 & & \\
\hline Past smoker & 71.7 & & \\
\hline Active smoker & 18.9 & & \\
\hline Period of disease, yrs & & $7.0(16.0)^{*}$ & $1.0-50.0$ \\
\hline
\end{tabular}




\begin{tabular}{|c|c|c|c|}
\hline Characteristics & $\%$ & Mean (SD) / Median (IQR)* & Range \\
\hline MRC dyspnea & & $2(2)^{*}$ & $0.0-4.0$ \\
\hline Grade 0 & 9.4 & & \\
\hline Grade 1 & 39.4 & & \\
\hline Grade 2 & 20.5 & & \\
\hline Grade 3 & 26.8 & & \\
\hline Grade 4 & 3.9 & & \\
\hline Admission & & $1(2)^{*}$ & $0.0-20.0$ \\
\hline$\leq 2$ times/yr & 79.5 & & \\
\hline$>2$ times/yr & 20.5 & & \\
\hline FEV1 ( $\%$ of predicted value) & & $70.0(9.6)$ & $45.7-79.9$ \\
\hline $\operatorname{BMI}\left(\mathrm{kg} / \mathrm{m}^{2}\right)$ & & $21.9(6.9)^{*}$ & $12.8-34.6$ \\
\hline$<21$ (underweight) & 51.2 & & \\
\hline$\geq 21$ (normal-overweight) & 48.8 & & \\
\hline PHQ-9 score $\geq 10$ & 37.8 & $8.3(6.0)$ & $0.0-22.0$ \\
\hline $6 \mathrm{MWD}(\mathrm{mts})<350$ & 82.7 & $256.6(98.3)$ & $30.0-420.0$ \\
\hline \multicolumn{4}{|l|}{ SGRQ score } \\
\hline Symptom & & $47.0(22.2)$ & $6.3-100.0$ \\
\hline Activity & & $49.7(30.3)$ & $0.0-100.0$ \\
\hline Impact & & $41.9(21.2)$ & $0.0-91.8$ \\
\hline Total & & $45.1(21.7)$ & 2.9-94.6 \\
\hline
\end{tabular}

Table 2 Correlation among domains of HRQL and related factors.

\begin{tabular}{lllll}
\hline Variables & Symptom & Activity & Impact & Total \\
\hline Admission $(\geq 2)^{\mathrm{a}}$ & $.279^{* *}$ & $.244^{* *}$ & $.210^{*}$ & $.257^{* *}$ \\
BMI $(<21)^{\mathrm{a}}$ & $.191^{*}$ & -.010 & .067 & .066 \\
MRC dyspnea (grade 0 - 2) & $-.294^{* *}$ & $-.533^{* *}$ & $-.455^{* *}$ & $-.510^{* *}$ \\
${\text { MRC dyspnea (grade } 3-4)^{\mathrm{a}}}$ & $.294^{* *}$ & $.533^{* *}$ & $.455^{* *}$ & $.510^{* *}$ \\
MMWD $^{\mathrm{b}}$ & $-.246^{* *}$ & $-.624^{* *}$ & $-.507^{* *}$ & $-.569^{* *}$ \\
PHQ-9 $^{\mathrm{b}}$ & $.321^{* *}$ & $.490^{* *}$ & $.552^{* *}$ & $.549^{* *}$ \\
\hline
\end{tabular}

${ }^{*} \mathrm{p}<0.05,{ }^{* *} \mathrm{p}<0.01,{ }^{\mathrm{a}}$ Spearman's rank correlation, ${ }^{\mathrm{b}}$ Pearson's product moment correlation. 
http://wjst.wu.ac.th

Table 3 Multiple regression analysis predicting each component of HRQL.

\begin{tabular}{|c|c|c|c|c|c|}
\hline \multirow[t]{2}{*}{ Predictors } & \multicolumn{2}{|c|}{$\begin{array}{l}\text { Unstandardized } \\
\text { coefficients }\end{array}$} & \multirow{2}{*}{$\begin{array}{c}\begin{array}{c}\text { Standardized } \\
\text { coefficients }\end{array} \\
\beta \\
\end{array}$} & \multirow[t]{2}{*}{$\mathbf{t}$} & \multirow[t]{2}{*}{$p$-value } \\
\hline & B & SE & & & \\
\hline \multicolumn{6}{|l|}{ Predicting symptom } \\
\hline Admission $(\geq 2)$ & 9.023 & 3.909 & .229 & 2.687 & .008 \\
\hline MRC Dyspnea (grade 0 - 2) & -9.235 & 4.119 & .196 & 2.308 & .023 \\
\hline PHQ-9 & .833 & .310 & -.193 & -2.242 & .027 \\
\hline \multicolumn{6}{|c|}{ Full model: $F_{(3,126)}=9.570 ; R^{2}=.189$} \\
\hline \multicolumn{6}{|c|}{ Predicting activity } \\
\hline 6MWD & -.115 & .024 & -.375 & -4.721 & .000 \\
\hline MRC Dyspnea (grade 3 - 4) & 16.727 & 4.937 & .256 & 3.388 & .001 \\
\hline PHQ-9 & 1.394 & .346 & .279 & 4.024 & .000 \\
\hline \multicolumn{6}{|c|}{ Full model: $F_{(3,125)}=41.813 ; R^{2}=.507$} \\
\hline \multicolumn{6}{|l|}{ Predicting impact } \\
\hline 6MWD & -.050 & .018 & -.233 & -2.745 & .007 \\
\hline MRC Dyspnea (grade 0 - 2) & -10.522 & 3.700 & -.230 & -2.844 & .005 \\
\hline PHQ-9 & 1.351 & .260 & .387 & 5.202 & .000 \\
\hline \multicolumn{6}{|c|}{ Full model: $F_{(3,125)}=31.097 ; R^{2}=.433$} \\
\hline \multicolumn{6}{|l|}{ Predicting total score } \\
\hline 6MWD & -.062 & .018 & -.282 & -3.497 & .001 \\
\hline MRC Dyspnea (grade 3 - 4) & 12.473 & 3.598 & .266 & 3.467 & .001 \\
\hline PHQ-9 & 1.293 & .252 & .361 & 5.122 & .000 \\
\hline Full model: $F_{(3,125)}=39.329 ; 1$ & & & & & \\
\hline
\end{tabular}

\section{Discussion}

Health-related quality of life (HRQL) defined as the degree to which a patient's health status affects his or her self-determined evaluation of satisfaction or quality of life [6,7], is an important prognostic factor in COPD patients. In the present study, we found the different domains of HRQL, it is remarkable to note that patients showed lower scores in the impact domain than the symptom or activity domains. The health-related quality of life was significantly associated with 3 predicting factors: exercise capacity, depression, and dyspnea-related limitation (grade 3 - 4) as follows:

Dyspnea is one of the main respiratory symptoms present during a stable or exacerbated state. It is caused by airflow obstruction which is secondary to airways inflammation, airways remodeling and sputum hyper-secretion; reduced lung elastic recoil due to emphysema and the obstruction of small airways result in incomplete air expelling and dynamic hyperinflation [29]. It is also one of the main determinants of HRQL in COPD patients, as previous studies have found moderate to high correlation between dyspnea and HRQL [5,30,31]. Our findings also provide further confirmation that the high severity of dyspnea associated with activities in daily life and impairment of HRQL. Accordingly, patients with high degrees of dyspnea have more restrictions on activities of daily living, and the disease has more impact on their life. In clinical practice, then, stratification according to the degree of dyspnea could be more useful than spirometry in determining COPD patients' self-perceived health status. The advantage of assessing MRC dyspnea is that, unlike quality of life questionnaires, very little time is needed to ask the patients what daily life activities cause breathlessness and the information is easily obtained while taking the patient's medical history [32]. 
http://wjst.wu.ac.th

Exercise capacity (6MWD) was located close to the self-reported data on physical function, correlating most strongly with the activity component. Moreover, exercise capacity is the only clinical measurement related to psychological wellbeing at the end of treatment, because exercise capacity was associated with a significant improvement in quality of life [33]. In this study, we have shown the association of decreased exercise capacity lead to limited activities and impaired HRQL. Factors behind 6MWD have not been systematically investigated, but 2 aspects have been described: body composition as muscle mass and fat mass [34] and psychological factors as poor social support and high barriers to less exercise [35].

Depression was found in $37.8 \%$ of cases, similar to previous studies from Korea and India, the prevalence of depression in patients with COPD has been reported from 23.8 to 33.3 percent [36,37]. In addition, the patients with COPD experienced markedly more depression compared with the healthy population [38]. Recent research confirms the relationship between depression and chronic illnesses such as COPD. Depression causes major disability effects with QOL [39]. This study found that depression was a significant predicting factor of all domains of health-related quality of life. However, it was strongly associated with impact domain, because the origin of the impact domain, covering psychological disturbances resulting from respiratory disease. Thus, regardless of results, health personnel should quickly assess the presence of depression in all COPD patients.

Finally, this study found that 2 factors of BMI and admission could not predict HRQL of stable COPD patients. However, it appears that poor symptom domains of HRQL related to a greater likelihood of admission to hospital. The reasons for admission are very complex and depend on severity of disease, and health status [40]. Previous prospective studies have shown that independent risk factors associated with readmission include: poor lung function, severe limitation in activity and poor health related quality of life $[41,42]$.

\section{Conclusions}

The associations found are therefore likely to reflect the factors determining impairment HRQL of stable COPD patients, including the important clinical outcomes of high degree of dyspnea, poor exercise capacity, and level of depression. It is thought that those clinical outcomes of stable COPD patients at the out-patient pulmonary clinic needed to be concerned. Pulmonary rehabilitation would be useful for stable COPD patients to maintain functional independence and increasing their HRQL. Further research is required to examine the effect of pulmonary rehabilitation at home on dyspnea, exercise capacity, admission and depression. In addition, this study has some limitations that should be mentioned. First, the study used a cross-sectional design and convenience sampling, and thus the study does not allow us to determine a causal relationship between related factors and HRQL. Finally, several factors that have been associated with HRQL, including social support, barriers to care, and spiritually, were not examined.

\section{Acknowledgements}

We would like to thank the Research and Development Institute, Walailak University for providing a research grant to support this study. Special heartfelt thanks to all participants.

\section{References}

[1] The Global Strategy for the Diagnosis, Management and Prevention of COPD, Global Initiative for Chronic Obstructive Lung Disease (GOLD) 2017. Available at: http://www.goldcopd.org, accessed March 2017.

[2] S Burapadaja, P Konkaew, P Tuntipathananandh and J Sanguansermsri. Effect of clinical practice guideline on therapeutic outcomes and treatment expenditures of COPD patients. Chiang Mai Univ. J. Nat. Sci. 2006; 5, 77-84. 
http://wjst.wu.ac.th

[3] N Noonil, S Sindhu, S Hanucharurnkul and N Suwonnaroop. An integrated approach to coordination of community resources improves health outcomes and satisfaction in care of Thai patients with COPD. Thai J. Nurs. 2007; 11, 118-31.

[4] PW Jones. Activity limitation and quality of life in COPD. J. Chron. Obstruct. Pulmon. Dis. 2007; 4, 273-8.

[5] JB Gruenberger, J Vietri, DL Keininger and DA Mahler. Greater dyspnea is associated with lower health-related quality of life among European patients with COPD. Int. J. Chron. Obstruct .Pulmon. Dis. 2017; 12, 937-44.

[6] SW Weldam, MJ Schuurmans, R Liu and JW Lammers. Evaluation of quality of life instruments for use in COPD care and research: A systematic review. Int. J. Nurs. Stud. 2017; 50. 688-707.

[7] JZ Reardon, SC Lareau and R ZuWallack. Functional status and quality of life in chronic obstructive pulmonary disease. Am. J. Med. 2006; 119, S32-7.

[8] A Yorgancioglu, Y Havlucu, P Celik, G Dinc and A Saka. Relation between quality of life and morbidity and mortality in COPD patients: Two-year follow-up study. J. Chron. Obstruct. Pulmon. Dis. 2010; 7, 248-53.

[9] I Henoch, S Strang, CG Lofdahl and A Ekberg-Jansson. Health-related quality of life in a nationwide cohort of patients with COPD related to other characteristics. Eur. Respir. J. 2016; 3, 18.

[10] JM Marin, CG Cote, O Diaz, C Lisboa, C Casanova, MV Lopez, SJ Carrizo, V Pin-Plata, LJ Dordelly, H Nekach and BR Celli. Prognostic assessment in COPD: Health related quality of life and the BODE index. Respir. Med. 2011; 105, 916-21.

[11] PW Jones, FH Quirk, CM Baveystock and P Littlejohns. A self-complete measure of health status for chronic airflow limitation: The St. George's Respiratory Questionnaire. Am. Rev. Respir. Dis. 1992; 145, 1321-7.

[12] SK Sarkar, S Basuthakur, SK Das, A Das, S Das, S Choudhury and S Datta. Evaluation of correlation of BODE index with health-related quality of life among patients with stable COPD attending a tertiary care hospital. Lung India 2015; 32, 24-8.

[13] JP Allinson, GC Donaldson, B Kowlessar, AJ Mackay, R Singh, SE Brill and JA Wedzicha. The independent effect of chronic bronchitis on Health-related quality of life In COPD. Am. J. Respir. Crit. Care Med. 2014; 189, A5929.

[14] A Blakemore, C Dickens, E Guthrie, P Bower, E Kontopantelis, C Afzal and PA Coventry. Depression and anxiety predict health-related quality of life in chronic obstructive pulmonary disease: systemic review and meta-analysis. Int. J. Chron. Obstruct. Pulmon. Dis. 2014; 9, 501-12.

[15] EA Regan, D Curran-Everett, KF Hoth, GR Washko, J Black-Shinn, CE McEvoy, NA Hanania, CA Meldrum, AM Boriek and JW Ramsdell. Worsening quality of life in COPD is associated with increasing dyspnea, reduced walking distance and baseline expiratory gas trapping. Am. J. Respir. Crit. Care Med. 2015; 191, A2839.

[16] SR Agrawal, R Joshi and A Jain. Correlation of severity of chronic obstructive pulmonary disease with health-related quality of life and six-minute walk test in a rural hospital of central India. Lung India 2015; 32, 233-40.

[17] C Bunnag, R Fuangtong, C Pothirat and P Punyaratabandhu. A Comparative study of patients' preferences and sensory perceptions of three forms of inhalers among Thai asthma and COPD patients. Asian Pac. J. Allergy Immunol. 2007; 25, 99-109.

[18] GL Biscione, L Mugnaini, F Pasqua, G Crigna, L Ferri, V Cardaci, M Fini, R Gargano and P Granone. A Cesario BODE index and pulmonary rehabilitation in chronic respiratory failure. Eur. Respir J. 2006; 27, 1320-26.

[19] JP de Torres, E Cordoba-Lanus and C Lopez-Aguilar. C-reaction protein levels and clinically important predictive outcomes in stable COPD patients. Eur. Respir. J. 2006; 27, 902-7.

[20] J Cohen. A power Primer. Psychol. Bull. 1992; 112, 155-9.

[21] National Institutes of Health, National Heart Lung and Blood Institute Obesity Education Initiative Expert Panel on the Identification, Evaluation, and Treatment of Obesity in Adults. Executive 
http://wjst.wu.ac.th

summary of the clinical guidelines on the identification, evaluation, and treatment of overweight and obesity in adults. Arch. Intern. Med. 1998; 158, 1855-67.

[22] BR Celli, CG Cote, JM Marin, C Casanova, MDO Montes, RA Mendez, VP Pinto and HJ Cabral. The body-mass index, airflow obstruction, dyspnea and exercise capacity index in COPD. New Eng. J. Med. 2004; 350, 1005-12.

[23] JC Bestall, EA Paul, R Garrod, R Garnham, PW Jones and JA Wedzicha. Usefulness of the Medical Research Council (MRC) dyspnea scale as a measure of disability in patients with chronic obstructive pulmonary disease. Thorax 1999; 54, 581-6.

[24] PW Jones, L Adamek, G Nadeau and N Nanik. Comparisons of health status scores with MRC grades in COPD: implications for the GOLD 2011 classification. Eur. Respir. J. 2013; 42, 647-54.

[25] JM Marin, CG Cote, O Diaz, C Lisboa, C Casanova, MV Lopez, SJ Carrizo, V Pin-Plata, LJ Dordelly, H Nekach and BR Celli. Prognostic assessment in COPD: Health related quality of life and the BODE index. Respir. Med. 2011; 105, 916-21.

[26] SJ Singh, MA Puhan, V Andrianopoulos, NA Hernandes, KE Mitchell, CJ Hill, AL Lee, CA Camillo, T Troosters, MA Spruit, BW Carlin, J Wanger, V Peplin, D Saet, DA Kaminsky, MC McCormack, N Maclntyre, BH Culver, FC Sciurba, SM Revill, V Delafosse and AE Holland. An official review of the European Respiratory Society/American Thoracic Society: Measurement properties of field walking tests in chronic respiratory disease. Eur. Respir. J. 2014; 44, 1447-78.

[27] M Lotrakul, S Sumrithe and R Saipanish. Reliability and validity of the Thai version of the PHQ-9. BMC Psychiatr. 2008; 8, 46-52.

[28] AS Moriarty, S Gilbody, D McMillan and L Manea. Screening and case finding for major depressive disorder using the Patient Health Questionnaire (PHQ-9): A meta-analysis. Gen. Hosp. Psychiatr. 2015; 37, 567-76.

[29] SA Antoniu. Descriptors of dyspnea in obstructive lung disease. Mul. Respir. Med. 2010; 5, $216-9$.

[30] M Justine, F Tahirah and V Mohan. Health-related quality of life, lung function and dyspnea rating in COPD patients. Monaldi. Arch. Chest Dis. 2013; 79, 116-20.

[31] A Ekici, E Bulcun, T Karakoc, E Senturk and M Ekici. Factors associated with quality of life in subjects with stable COPD. Respir. Care 2015; 60, 1585-91.

[32] S Jogesh and K Gitumoni. Impact of psychosocial factors on health-related quality of life in chronic obstructive pulmonary disease patients. J. Psychiatr. Allied Sci. 2015; 6, 20-7.

[33] N Zoeckler, K Kenn, K Kuehl, N Stenzel and W Rief. Illness perceptions predict exercise capacity and psychological well-being after pulmonary rehabilitation in COPD patients. J. Psycho. Res. 2014; 76, 146-51.

[34] MH Jung, SH Ihm, DH Lee, HW Park, Y Choi, WB Chung, HO Jung and HJ Youn. Factors determining exercise capacity in community-dwelling apparently healthy subjects. J. Hypertens. 2016; 34, e482.

[35] LB Cooper, RJ Mentz, JL Sun, PJ Schulte, JL Fleg, LS Cooper, IL Pina, ES Leifer, WE Kraus, DJ Whellan, SJ Keteyian and CM O'Connor. Psychological factors, Exercise adherence, and Outcomes in Heart Failure Patients. Circ. Heart Fail. 2015; 8, 1044-51.

[36] YS Lee, S Park, YM Oh, SD Lee, SW Park, YS Kim, KH In, BH Jung, KH Lee, SW Ra, YI Hwang, YB Park and KS Jung. Chronic obstructive disease assessment test can predict depression: a prospective multi-center study. J. Korean Med. Sci. 2013; 28, 1048-54.

[37] H Negi, M Sarkar, A Raval, K Pandey and P Das. Presence of depression \& its risk factors in patients with chronic obstructive pulmonary disease. Indian J. Med. Res. 2014; 139, 402-8.

[38] TS Wong, YT Xiang, J Tsoh, GS Ungvari, FW Ko, DS Hui and HF Chiu. Depressive disorders in older patients with chronic obstructive pulmonary disease (COPD) in Hong Kong: A controlled study. Aging Ment. Health. 2014; 18, 588-92.

[39] A Baraniak and D Sheffield. The efficacy of psychologically based interventions to improve anxiety, depression and quality of life in COPD: A systematic review and meta-analysis. Patient Educ. Couns. 2011; 83, 29-36. 
http://wjst.wu.ac.th

[40] G Gudmundsson, T Gislason, C Janson, E Linberg, R Hallin, CS Ulrik, E Brondum, MM Nieminen, $\mathrm{T}$ Aine and P Bakke. Risk factors for rehospitalisation in COPD: Role of health status, anxiety and depression. Eur. Respir. J. 2005; 26, 414-9.

[41] P Almagro, B Barreiro, EA Ochoa, S Quintana, CM Rodriguez, JL Heredia and J Garau. Risk factors for hospital readmission in patients with chronic obstructive pulmonary disease. Respiration 2006; 73, 311-7.

[42] PA Coventry, I Gemmell and CJ Todd. Psychosocial risk factors for hospital readmission in COPD patients on early discharge services: A cohort study. BMC Pulmon. Med. 2011; 11, 49-58. 